\title{
CONVERSATIONS ON AN EMBEDDED PHONE WHILE DRIVING: PREDICTED VS. OBSERVED REAL-WORLD AIRBAG DEPLOYMENT CRASH RATES
}

\author{
Richard A. Young ${ }^{1}$ and Chris Schreiner ${ }^{2}$ \\ ${ }^{1}$ General Motors Engineering \\ 30200 Mound Rd \\ Warren, MI 48092 \\ E-mail: richard.a.young@gm.com \\ ${ }^{2}$ Motorola
}

PAPER NOT AVAILABLE

\begin{abstract}
\section{OBJECTIVE}

To evaluate hypotheses that may help explain the discrepancy between the predicted vs. observed real-world airbag-deployment crash rates during conversation on a mobile phone embedded in a vehicle.
\end{abstract}

\section{METHOD}

Previous epidemiological, laboratory, and closed-road studies predict a 2-8 times increase in relative risk of phone conversations during real-world driving compared to baseline driving. Counts of real-world crashes clearly associated with portable cell usage are difficult to obtain and incomplete. However a large and complete body of real-world data exists of conversation usage on mobile phones embedded in vehicles and crashes severe enough to deploy an airbag (Young, 2001). The degree of discrepancy between the observed numbers of real-world crashes in these studies and the predicted risks of wireless conversations from previous studies is calculated. Hypotheses are presented and evaluated that may help to explain the discrepancy.

\section{RESULTS}

The absolute frequency of airbag deployment crashes occurring during conversation on a wireless phone embedded in a vehicle is low, and the relative airbag deployment crash rate is no greater than baseline driving. The pros and cons of five hypotheses are evaluated to help explain the discrepancy from previous studies predicting an increased crash rate from wireless phone conversations in general: (1) the reaction time increase arising from conversations in previous studies may be too small to give rise to a detectable increase in real-world crash rates; (2) labbased event detection does not account fully for similar types of event detection in real driving, let alone for crashes (Angell et al., 2006; Curry et al., 2005; Young et al., 2005); (3) conversation may at times mitigate risks such as fatigue; (4) portable and embedded cell phones may have substantially different human factor properties; and (5) drivers may tend to change behavior during calls in ways that reduce net risk: place calls in relatively benign driving conditions, reduce risky driving maneuvers, increase headway, glance longer to the forward roadway, increase glances to mirrors after an event. 


\section{CONCLUSIONS}

The observed real-world airbag-deployment crash rate during conversations on an embedded hands-free device is substantially lower than predicted by previous simulator, closed-road, or epidemiological studies. Several hypotheses, if validated, may help resolve the discrepancy.

\section{REFERENCES}

Angell, L.S., Auflick, L.L., Austria, P.A., Kochhar, D.S. \& Tijerina, L. (2006). Driver workload metrics project: Task 2 final report. Submitted to U.S. Dept. of Transportation, FHA, \& NHTSA under Cooperative Agreement Number DTFH61-01-X-00014.

Curry, R.C., Greenberg, J.A., \& Kiefer, R.J. (2005). NADS versus CAMP closed-course comparison examining 'last second' braking and steering maneuvers under various kinematic conditions. Crash Avoidance Metrics Partnership (CAMP), Contract DTFH61-01-X-00014, Washington, DC, August, DOT HS 809925.

Young, R. (2001). Association between embedded cellular phone calls and vehicle crashes involving air bag deployment. Proceedings of Driving Assessment 2001: International Symposium on Human Factors in Driver Assessment, Training and Vehicle Design, Snowmass, Utah, August, 390-400.

Young, R.A., Aryal, B.J., Muresan, M., Ding, X., Oja, S. \& Simpson, S. (2005). Road-to-lab: Validation of the Static Load Test for predicting on-road driving performance while using advanced in-vehicle information and communication devices. Proceedings of the Third International Driving Symposium on Human Factors in Driver Assessment, Training and Vehicle Design, Rockport, Maine, July, 240-254. 